\title{
Is Dietary Supplement (Health Food) Useful for Maintenance of Health?
}

\section{Hideharu Shintani*}

Chuo University, School of Science, 1-13-27, Kasuga Bunkyo 112-0003, Tokyo, Japan

Dietary supplement is not replacement of medical drug. Even though both contain same components, dietary supplement and medical drug quite differ.

Recently, in the market dietary supplement containing same tradename of medical drug is available. Most of the consumer considers that medical drug has a severe side effect, but dietary supplement has not. Medical drug is synthetic, so dangerous, but dietary supplement is natural, so safer, which is misunderstanding. Dietary supplement can be available without doctor's prescription.

Dietary supplement is food, not medical drug. Even if same components may contain, dietary supplement is not use for the treatment of patients contrary to the medical drug. The difference of dietary supplement and medical drug is presented in the following Table.

From the above table you may consider there are significant difference between medical drug and dietary supplement (health food).

Medical drug produced under certain quality at pharmaceutical companies and quantity is strictly controlled according to the pharmacopeia. In order to confirm validity and safety of the practical medicine, many patients are clinically tested in Class III. Medical drug can be tested in the order of in vitro test (test tube test) $\rightarrow$ in vivo test (animal test) $\rightarrow$ Clinical test (Class I, II and III) to confirm scientific rationale (evidence of the quality and safety). Strictly controlled manufacturing process and Class III test using real patients was conducted to confirm validity and safety of medical drug. From these tests, validity and safety of the medical drug can be officially labeled.

On the contrary, dietary supplement (health food) has no regulation and standard to prepare. Scientific rationale (evidence of validity and quality) are not always clarified, some dietary supplement is said to be effective from the data of in vitro and in vivo test skipping Clinical test. The results of in vitro and in vivo test are not always identical to Clinical test. Most of dietary supplement is not carried out clinical test, so quality and validity are neglected.

For example, ornithine is the component used as medical drug and also diatry supplement. It is classified as medical drug or dietary supplement if it is passed a strict testing or not. In case of dietary supplement, quantity of the tablet is unreliable. Therefore, in case of medical drug, it can sell by labeling validity and efficacy, but dietary supplement (health food) cannot. Medical drug can be applied to the treatment of the patients but dietary supplement cannot,

To judge the safety there is no rationale if it is natural or synthetic. To judge the safety it is necessary quantity (does). Medical drug is safe because the dose per day is clarified based on the several tests including clinical test. On the contrary, the quantity of the dietary supplement is not always clarified. If un-clarified, safety dose is also not clarified.

As mentioned above, dietary supplement is food. Food is not applied to the treatment of disease. This is the same as in Food for Specified Health Use (FOSHU) and Qualified FOSHU. Dietary supplement (health food) is not replacement of medical drug. If you feel any abnormality in your body, not reply on dietary supplement, but medical doctor to be applied medical drug.

\begin{tabular}{|c|c|c|}
\hline & Medical drug & Dietary supplement \\
\hline target & patients. treatment purpose & $\begin{array}{l}\text { healthy person. not } \\
\text { approved for treatment use }\end{array}$ \\
\hline quality & $\begin{array}{l}\text { following the production } \\
\text { standard and quality control } \\
\text { standard (GMP, good } \\
\text { manufacturing practice), } \\
\text { a certain quality level of } \\
\text { medicine is produced. } \\
\text { Analytical procedures of } \\
\text { components are presented. } \\
\text { The amount of quantity is } \\
\text { clarified. }\end{array}$ & $\begin{array}{l}\text { Even if the name is } \\
\text { identical to medical drug, } \\
\text { quantity is not always } \\
\text { public. No regulation } \\
\text { is addressed for the } \\
\text { production of dietary } \\
\text { supplement. }\end{array}$ \\
\hline $\begin{array}{l}\text { Scientific } \\
\text { rationale } \\
\text { (evidence) }\end{array}$ & $\begin{array}{l}\text { Test of safety and validity } \\
\text { are performed following the } \\
\text { guidelines. Treatment of the } \\
\text { disease and the validity of } \\
\text { the medicine are confirmed. } \\
\text { Clinical test to patients as } \\
\text { Class I, II and III can be } \\
\text { performed before practical } \\
\text { use to the patients. }\end{array}$ & $\begin{array}{l}\text { Scientific safety and } \\
\text { validity are not unclear. } \\
\text { Component information is } \\
\text { from product information. } \\
\text { Safety and validity of the } \\
\text { products are not tested. } \\
\text { Safety tests using patients } \\
\text { are not conducted. As } \\
\text { clinical test was not } \\
\text { conducted, so validity is } \\
\text { not confirmed. }\end{array}$ \\
\hline Use & $\begin{array}{l}\text { Medical drug can be utilized } \\
\text { under the appropriate } \\
\text { suggestion and advice of the } \\
\text { doctor or pharmacist. }\end{array}$ & $\begin{array}{l}\text { Mostly base on the } \\
\text { self-judgment, dietary } \\
\text { supplement is utilized. } \\
\text { In some cases, dietary } \\
\text { supplement is sold without } \\
\text { knowledge of dietary } \\
\text { supplement because } \\
\text { there is no regulation for } \\
\text { the trade in the dietary } \\
\text { supplement. }\end{array}$ \\
\hline
\end{tabular}

*Corresponding author: Hideharu Shintani, Chuo University, School of Science 1-13-27, Kasuga Bunkyo 112-0003, Tokyo, Japan, Tel: +81425922336; E-mail: shintani@mail.hinocatv.ne.jp

Received September 13, 2013; Accepted September 15, 2013; Published September 17, 2013

Citation: Shintani H (2013) Is Dietary Supplement (Health Food) Useful for Maintenance of Health? Adv Pharmacoepidemiol Drug Saf 2: e123. doi:10.4172/2167-1052.1000e123

Copyright: ( $) 2013$ Shintani H. This is an open-access article distributed under the terms of the Creative Commons Attribution License, which permits unrestricted use, distribution, and reproduction in any medium, provided the original author and source are credited. 